\title{
A GUIDE TO ABORIGINAL RECORDS
}

During 1992 Australian Archives will publish a select guide to records held by its ACT Regional Office which are relevant in some way to Aboriginal people. The material to be included was recorded in the period between 1860 and 1960, most of it between 1911 and 1952. This volume will be followed by a similar volume about records held by the Northern Territory Regional Office. The guide was compiled by Ros Fraser between 1979 and 1983, with the assistance of grants from the AIAS (now the Australian Institute of Aboriginal and Torres Strait Islander Studies), and partial drafts have been available at both AIATSIS and Australian Archives since 1980.

Official records are one of the sources which can be used in interpreting history. While they do not meet some of the needs of people involved in Aboriginal history, their particular chronicle of policy, administrative actions and events not only reveals the nature of policy and administration, but may provide a useful source of information for personal, family, community and other kinds of history. The majority of the items in both volumes of the guide relate to Commonwealth administration of the Northern Territory, but there is also material relevant to people in the states.

The ACT volume includes some of the records of some 42 Commonwealth government agencies. Some of these departments generated many relevant records, others were not directly connected with Aboriginal affairs and recorded only a small amount of material. A brief note is usually included about the structure and functions of each agency, and how it came to have created relevant records, with a select list of its record series; over 200 series are listed, and others are referred to in the text. Items from some of these series also have been listed, either as examples of the kinds of things that might be found in the series, or as more comprehensive selections. Approximately 4,000 files and photographs are individually listed in this way, and pointers are given for finding others. About 850 of the item entries also have been annotated to give some idea of what is in the files they describe.

A partial index which includes name, place and subject components is included. The intention of this finding aid is to index all file titles, and also to give access to some of the known content of some files, whose content would otherwise not be apparent from file titles or the text of the guide.

The size, scope and structure of the Northern Territory volume will be very similar to that of the ACT volume. Each volume may retail for less than $\$ 20$. For further information contact Gabrielle Hyslop, Assistant Director, Information Services, Australian Archives, PO Box 92, Mitchell, ACT, 2911. Phone (06) 2099489. 